\title{
Bus driver accident record; the return of accident proneness
}

\author{
Anders af Wåhlberg* (1) \\ and \\ Lisa Dorn (2)
}

1. Department of Psychology

Uppsala University

P. O. Box 1225

75142 Uppsala

Sweden

e-mail: anders.af_wahlberg@psyk.uu.se

Homepage: http://www.psyk.uu.se/hemsidor/busdriver

Tel: +46-18-471 25 90, +46-18-33 9095

2. Department of Human Factors,

Cranfield University, Cranfield, Bedfordshire, MK43 0AL

UK

* corresponding author 


\begin{abstract}
One of the assumptions of the theory of accident proneness is that drivers' accident liability is stable over time which was tested in the present paper. Previous investigations of this problem (or rather the conclusions) were found to be deficient, because they did not take into account the statistical problem of low variance in the accident variable. However, by correlating the between time periods association coefficient and the mean number of accidents across several samples, this problem can be overcome. Therefore, the stability of accident record over time was investigated in five samples of British bus drivers. It was found that the size of the correlations between time periods increased with the increase in mean accident frequency. Furthermore, this increase could be described by a linear regression line, which fit the various points extremely well. Also, the size of correlations of At fault accidents increased faster with the mean than did All accidents, although the latter had a higher initial value. It was therefore concluded, in contrast to previous authors, that the accident record of drivers is quite stable over time, and that the very low correlations which have often been found were due to the samples and methods used (low-risk drivers and short time periods equalling low crash means), and not of any inherent instability in drivers' behaviour and/or accident record. It was also concluded that only culpable accidents should be used for this type of calculation. No evidence was found for a decrease in correlation size between single years' accidents when time periods between the years were lengthened, i.e. accidents in one year predicted accidents in several other years equally well. However, the period used was rather short. The results are discussed with reference to training intervention for accident -involved drivers, especially for organizations with major fleets such as bus companies.
\end{abstract}

Key words: accident proneness, bus driver, crash, reliability, stability, accident record 


\section{Introduction}

\subsection{History and theory of accident proneness}

The beginning of safety research has often been traced to British studies about the distributions of accidents in various populations (mainly industrial workers) in the early 20th century (e.g. Greenwood \& Woods, 1919; Newbold, 1927; Slocombe \& Brakeman, 1930). One of the main hypotheses was that accidents were not random events for workers, but in some way were due to stable individual difference in their behaviour. This was the origin of the research tradition of accident proneness.

The early work concluded that some people are clumsy, or risk seeking, and therefore cause more damage to themselves and their surroundings than their more safety-minded peers, a notion with quasi-theoretical properties. For example, one major prediction that could be drawn from this general line of thinking was that people would tend to be stable over time in their accident proneness, meaning that their numbers (or rates) of accidents would tend to be the same in different time periods, at least within the same environment. This reasonable way of thinking did also yield some positive results when empirical testing was undertaken (e.g. Newbold, 1927; Wong \& Hobbs, 1949; Adelstein, 1952), before many researchers turned to statistical quarrelling (Mintz \& Blum, 1949; Maritz, 1950; Mintz, 1954; 1956), and progress was halted.

The accident proneness concept was imported into the fledgling traffic research field (Farmer \& Chambers, 1929; 1939), along with the basic controversy of whether it actually exists. While statisticians were mainly interested in how various theoretical distributions could be fitted against data, and what the results could possibly mean, many traffic researchers studied the stability of accidents over time (which had generated the positive results for industrial accidents). At first, it was claimed that a small number of drivers within a time period were responsible for a fairly large number of accidents (e.g. Baker, 1929; 1932; Tillman \& 
Hobbes, 1949). However, it was soon found that there were actually very low correlations between accidents in different time periods (e.g. Forbes, 1939; Kerr, 1957). Also, removing the drivers with many accidents in one time period would actually have very little effect in reducing crashes, because those with multiple accidents were few and far between. With time, the traffic accident proneness concept fell into disrepute, with many critics (Kirchner, 1961; Cameron, 1975; McKenna, 1983) and hardly any defenders (for a review, see Porter, 1988). Most traffic researchers who studied the question empirically came to the conclusion that there was very little stability over time (e.g. Harrington, 1972) as did accident researchers in general (e.g. Arbous \& Kerrich, 1951), due to the fact that most of the correlations between time periods were extremely small. Today, there seem to be little interest in the question of whether (traffic) accident record is a stable individual differences variable (Gebers, 2003, is one of the exceptions).

In the present paper, some of the assumptions, methods and conclusions by previous researchers regarding whether accident record is stable over time will be challenged as erroneous, and alternative ways of investigating this question suggested and used. The subjects covered are; how to analyse and interpret the sizes of accident correlations between time periods, using all accidents versus culpable ones, and the effect of correlating accidents in non-adjacent periods.

The notion of accident proneness used in the present study does not assume anything about its relation to personality or other personal variables, but is simply the statement that people are differently prone to causing accidents, in a similar environment, and that this is a trait that is stable over time.

\section{Methodological and statistical background}


The rejection of the stability over time part of accident proneness did not take into consideration a number of facts, which, if properly evaluated, point in quite another direction; firstly, early studies on workers' accidents did often find sizeable (>.20) correlations between time periods (e.g. Greenwood \& Woods, 1919; Newbold, 1927; Farmer \& Chambers, 1939); secondly, a number of studies of professional drivers have reported fairly strong (>.40) associations over time (e.g. Creswell \& Froggatt, 1963; Bach, Bickel \& Biehl, 1975; Milosevic \& Vucinic, 1975; Blasco, Prieto \& Cornejo, 2003); thirdly, low correlations have almost all been found in car driver populations (e.g. Forbes, 1939; Burg, 1970; Stewart \& Campbell, 1972; Peck, 1993); finally, culpability for accidents have seldom been included in the analyses. The first three observations are all part of the same problem, and the solution when it comes to reconciling them is that the weak associations have most often been calculated on rather short time periods for low-risk groups, resulting in very low means and standard deviations, which necessarily mean low statistical associations (Peck, 1993). The very differing levels of correlations in different studies are therefore a natural result of differences in mean number of accidents in the samples for the time periods used. In the words of Arbous and Kerrich (1951): "In fairness to the theory of proneness, however, it must be pointed out that as the successive exposure periods are increased, the correlation coefficient will also increase..." (p. 369). Although this statement was about increasing the variance within a sample by using longer time periods for calculations, the same principle is valid for comparisons between samples; those with higher means/variances will yield stronger associations between periods. So, if association data from several studies is gathered, it can be shown that it is the time period used for calculation and/or the mean number of accidents in the sample which almost exclusively (70-80 percent of the variance) determines the size of the correlation between time periods (af Wåhlberg, forthcoming, see Figure 1). 
Figure 1 about here

The conclusion drawn from this result is that the liability to have accidents is not only differently distributed in a population, but it is also surprisingly stable over time within each individual (note that most drivers in a year will have no accidents, as will they in the next year, an amazing stability that is not reflected by a correlation). The scientific and statistical problem is that this level of proneness is so low that it cannot be reliably determined or even detected using such time periods and populations as most researchers have utilized. However, if the principle of the mean accident level as predictor of the correlation between time periods holds good between samples and populations, it should also be the case for samples from a single population, if these have different mean levels of accident frequency. This hypothesis can be tested by drawing different samples from a population, correlating their accidents for different time periods and plotting these correlations against the accident means.

Furthermore, the correlations can be calculated for differing time periods for each sample and compared to the means.

It can be noted that most researchers studying the association of crashes between time periods have used all accidents in their calculations, regardless of culpability. However, the concept of accident proneness was really about causing accidents, not about random events, which had nothing to do with the behaviour of the accidentee. Therefore, unless some sort of stable differential environmental risk creates a biased risk exposure, the accidents for which the driver is not responsible should not be included, because they add error variance. However, of the few researchers who have compared the stability of all accidents with that of culpable only (Häkkinen, 1958; Harrington, 1972; Gebers \& Peck, 1994; Gebers, 2003; see also West, Elander \& French, 1992, who used the active/passive distinction), no one has concluded that this method had an advantage over using All accidents. 
There are several possible reasons for this, for example that culpability is very difficult to ascertain, which adds error variation, due to erroneous categorizing. However, two other methodological problems can be suspected as the main culprits; lower means for culpable accidents, and that the criterion is erroneous. As stated, the size of an accident intercorrelation between time periods would seem to be dependent on the sample mean, and not much else. But this means that a comparison between all and culpable accidents for the same sample is unfair, because the latter will have less variation to work with statistically. Regarding the criterion, culpability should mean that the drivers were to some extent a cause of the event due to their driving behaviour. However, criterions for this would seem to differ between studies, because, although the criterion itself is almost never reported, the differing percentages of culpable drivers between studies (compare for example Cation, Mount \& Brenner, 1951; Brandaleone \& Flamm, 1955; Quimby, Maycock, Carter, Dixon \& Wall, 1986; Dobson, Brown, Ball, Powers \& McFadden, 1999), as well as the correlations between culpable and non-culpable in different studies (e.g. Goldstein \& Mosel, 1958; McBain, 1970; Gully, Whitney \& Vanosdall, 1995; Arthur \& Graziano, 1996), show that in many cases, the criterion does not achieve what it set out to do with any large degree of precision (af Wåhlberg \& Dorn, 2007). So, although most of the researchers who have used culpable accidents have found lower correlations between time periods, as compared to all accidents, and concluded that the effect of such restrictions are negative, they have not taken into account the effect of the lowered mean, or checked their culpability criterion for correctness. In fact, the first is not really possible to do until a fair amount of research has been conducted and a meta-analysis has determined the regression equations for the separate accident populations' stabilities. With these regressions the stability correlation for a given mean of accidents can be compared, and it can be ascertained which set of accidents achieve the highest stability with this given variation. Whether culpability has been assigned correctly 
within a set of accidents has hitherto been hard to ascertain. However, such methods have now been invented and tested upon the present data, showing a certain amount of error (af Wåhlberg \& Dorn, 2007). This will be further described in the method section.

Returning to the problem of stability of accident record over time, it can be noted that if there is little stability, then correlations between time periods further apart would be expected to be lower than for those in closer proximity, as claimed by Milosevic and Vucinic (1975) to be the case for their data. This question has rarely been posed, and so it was added to the present study. No prediction was made concerning these results, because the accident proneness concept does not really take into consideration this question.

It can be noted that professional populations (like the bus drivers in the present study) might be subject to attrition due to accidents (i.e. those who have many incidents leave the company), as shown for industrial workers by van Zelst (1954). For the presently used population, this has not been studied, and the only research on bus drivers' attrition seem to be af Wåhlberg (2005), where there was only a non-significant difference. However, if drivers with many crashes have left the company that supplied the present data, this would lead to an underestimation of the effect, due to restricted variance in the samples. Furthermore, the issue of unequal risk exposure has always been a problem of accident proneness studies; could it be the case that stability over time is due to some persons move about in riskier environments? For bus drivers, the only known calculation on this problem was undertaken by Häkkinen (1958), who concluded that the influence of differential risk between different bus routes was negligable. In the present study, unequal risk exposure cannot be ruled out, although the drivers did serve on several different routes (see further the method section).

To sum up, the aim of the present paper was to consider the validity of the major tenet of the accident proneness theory by investigating whether propensity to be involved in a crash is 
stable over time, utilizing two methods. First, it was investigated whether the intercorrelations between accidents in different time periods are determined by the mean level of accidents in the sample. It was predicted that when intercorrelations between periods were plotted against the mean accident levels for the total periods, they would conform to an almost perfect linear trend. Second, the trend for culpable accidents should be higher intercorrelations for the same mean when compared to all accidents. Also, the effect of time in between accident time periods on their intercorrelations was studied.

\section{Method}

\subsection{Subjects and data}

A UK bus company made traffic accident data available for analyses from five different geographical regions for the time period 2001-2005. All drivers in the samples had been driving for the whole period under investigation. These drivers used several different types of vehicles, from minibuses to double deckers, and drove both rural and urban routes. All incidents whilst at work are reported within this company. For accidents, a special form is completed, describing various circumstances, like driver manoeuvres before the crash. From this and other material, the area manager in collaboration with an insurance team assigns responsibility for the crash to the bus driver, at three levels; none fault, part fault and sole fault.

Each bus driver is allocated to a rota during their working week. Across all UK depots the rota typically includes between 2 and 4 routes. Some depots, particularly in heavily built up areas, may have between 10 and 15 routes to be driven across a rota. For the present samples, the number of routes driven per working week ranged from 2 to 15 and these tend to be 
driven by the same bus drivers operating from the same rotas week in and week out. A driver may swop their rota with another driver if they would like a change of shift. Whilst most drivers are experienced in the routes they drive, if they swop rotas as a novice bus driver they may not have encountered the route before. Given that there is a greater percentage of experienced drivers compared with novice drivers within a typical depot and swopping rotas tends to happen only occasionally, this eventuality is less common.

Only a very small percentage of drivers change depots often due to staff shortages in built up areas. With this as the exception, the vast majority of bus drivers stay with the same depot for the duration of their service. When they are transferred to another depot, every driver undergoes route risk assessment training. Route risk assessment includes a video of the road features that are problematic and associated with previous crashes. A mentor also accompanies the driver on the first drive of the route.

Data was arranged with driver as the unit of analysis, split by calendar year and culpability. For the present study, two accident variables were used; All (all levels of culpability added), and At fault (Part and Sole fault added). The basic variable was thus the number of accidents within a year for each driver. For some calculations, these years were added to longer periods.

However, for the present data, it has been shown that the criterion for culpability used by the company is too lenient (af Wåhlberg \& Dorn, 2007), meaning that several percent of accidents that should have been classified as culpable have not been designated as such. Therefore, the present data were not optimal for showing the proposed effects concerning culpability. The means of accidents and some other descriptive data are shown in Table 1.

Table 1 about here 


\subsection{Methods of analysis}

There are different ways of calculating the stability of accident record over time. The simplest and most common is to take two time periods and correlate the numbers in each for the drivers. In the present paper, additional methods were needed to show, not just the size of the correlation, but how the intercorrelations increased predictably when data was aggregated over periods, and how similar this increase was between groups of drivers defined by different culpability levels, and also by different means. To achieve this goal, a series of correlations need to be calculated. With a long time period available, the best method would be to start with each year in isolation and correlate it with all other years, thereafter computing the mean of the correlations, thus counteracting some of the randomness of accident rates. For the next step two-year periods would be used, and so on until only two periods were left. However, in the present data, the time period was too short for such a strategy (as the time period is doubled in every step). Therefore, aggregation was instead undertaken in smaller steps; first one year for each variable (accidents in 2001+2002 correlated with $2003+2004)$, and then the only year left added $(2001+2002$ versus $2003+2004+2005$ ), yielding three different levels of aggregation (total time periods two, four and five years) in five samples, resulting in fifteen correlations and their accident means, for All accidents and At fault accidents, respectively. In principle, however, any aggregation principle should have yielded the same result in the last analysis (association of correlations and means). The only critical issue is whether there is enough difference in the accident means for an association to become evident.

The expectation was that, as the number of correlations forming the mean decreased, and the time period and mean number of accidents in each necessarily increased, so would the mean correlation between time periods. As the culpability category necessarily differs from All 
accidents in mean number of incidents, it was therefore expected that each level would have its own unique regression line (see Statistical methods) when means and correlations were correlated, but also that this regression line would show a slightly stronger association for the culpable accidents at the same mean number of crashes.

\subsection{Statistical methods}

The preferred statistical tool for the analysis was Pearson correlation. Although this method may in some respects not be optimal for accident data, there was really no alternative, as it was imperative that the present results could be compared to those of other studies on the stability of accident record, almost all of which have used Pearson correlations (e.g. Häkkinen, 1958; Peck, McBride \& Coppin, 1971; Peck \& Kuan, 1983; Gebers, 2003). Also, it has been found that using raw data of this type, or log transformation (which have been recommended as a countermeasure against skewness), does not yield any differences (e.g. Avolio, Kroeck \& Panek, 1985).

As ten different correlations were to be computed for the one-year periods, these needed to be averaged for each time period (or a differing number of associations would have resulted where only one was wanted). This was done by squaring each correlation into explained variance, calculating the mean of these values and then taking the square root of this number. Finally, the average correlations computed can be plotted against the total mean number of accidents for both samples, in fact creating a correlation scatter plot. With this tool, it has previously been found that the intercorrelations between time periods are largely determined by the mean (af Wåhlberg, forthcoming), as shown in Figure 1.

\section{Results}


First, accidents were correlated between single years for the two accident variables (All and culpable only) for all samples (see Table 2), and the means of these associations computed (first section of Table 3). Thereafter, accidents were aggregated in steps (years added into longer periods) and correlated (sections two and three of Table 3). Second, the correlations of each aggregation level in all samples were correlated against the mean number of accidents (shown in Table 3) per total time period for each correlation, yielding an $\mathrm{r}$ of .91 $(\mathrm{N}=30$, $\mathrm{p}<.001)$

Tables 2-3 about here

Also, separate correlations were run for At fault and All accidents correlations against the means of the variables, resulting in very similar values $(.891$ and $.923, \mathrm{~N}=15$ for each and $\mathrm{p}<.001)$. Four fifths of the variation in correlation size was therefore explained by the mean number of accidents in the variables that were correlated. However, of more interest are the regression equations for these correlations, were the $\mathrm{r}$ of All accidents equal $0.128+0.0716^{*}$ accident mean, and At fault accidents equal $0.098+0.1090^{*}$ accident mean. This means that although All accidents initially (short time periods) have a higher stability, the increase with higher accident means for At fault accidents is stronger, and at 0.82 accidents, both will achieve r's of .187.

Third, mean correlations for single years against single years (Table 2) were computed by their proximity in time to the other year, with results that are shown in Table 4. There was no trend in the data, as the first and third values were almost exactly the same for both culpability categories, while the middle value differed somewhat, but in different directsions for the categories. 
Finally, experience was added as a factor in the analysis, by separating each sample into those drivers with less than a year's experience in the beginning of 2001, and others. This uneven split of the samples was due to the fact that the effect of experience on accidents for these drivers is only discernible in the first few years. Thereafter, there is no decline in accident rate (Dorn \& af Wåhlberg, in press). The accidents for the high/low experience groups were correlated for 2001 versus 2002 and 2001-2002 versus 2003-2005 for all samples except number 3, as there were very few inexperienced drivers in that set. The resulting correlations were plotted against the accident means of the total time periods, with a result that can be seen in Figure 2. It can be noted that despite the low numbers of drivers in the inexperienced groups $(\mathrm{N}=31-77)$ and the resulting possibility for chance deviations, the correlations still largely conformed to a straight regression line, with half the variation in correlation size explained by the mean number of accidents in the period.

Table 4 and Figure 2 about here

\section{Discussion}

\subsection{Results}

The results of the present analysis would seem to support the hypotheses stated in the introduction. The size of the intercorrelation between accidents in different time periods does seem to increase fairly monotonically with the mean in the sample for both accident variables. However, it is possible that this increase is not linear between accidents and the correlation, but rather the percentage of explained variance, where each numerical step indicates a similar difference in strength. Samples with much higher means are needed to test this, as correlation size and percentage of explained variance do not differ much at the lower end of the scales. 
The difference in regression equations between culpable and All accidents could be an effect of exposure. In the present study, exposure was only handled by arranging data per year. However, the drivers will be driving for differing amounts of hours with each individual probably tending to work a similar number of hours from one year to the next, i.e. hours worked correlate between years. Such a short-term stability of exposure would create an initial stability of the accident record, especially the non-culpable crashes, but would not increase as strongly with time, because hours of work would tend to shift somewhat randomly, and eradicate the effect. This hypothesis is in principle testable in the present data, but the results would be hard to interpret, for several reasons. First, the time frame needed for the expected curvilinearity of the association to emerge would probably be at least twice as long as the available series of accident data. Second, as the non-fault category in the present data probably contains a proportion of accidents, which should not have been designated as such, the effect can be expected to be weak. Third, as exposure data was not available, it was not possible to calculate how strong the stability of exposure effect could be expected to be. However, in a similar sample of drivers, it has been found that holding exposure constant had a very slight negative effect on at fault accident correlations, but a positive, equally slight, effect on All accidents (af Wåhlberg, submitted). This would seem to indicate that some of the stability in accident record is indeed due to differential and stable exposure, but only for non-culpable crashes. Therefore, if such an effect is at work in the present data, it can be expected to be small.

No decrease in correlation strength was evident when time periods were not adjacent, although the periods used were the same length as those of Milosevic and Vucinic (1975), who claimed to have found such an effect. However, although such a change could exist, it is probably rather small, and thus not detectable in the present samples. 
From the comparison of experienced to inexperienced drivers can be concluded that it is not mainly the difference in experience that has an impact upon the correlations between time periods. It could otherwise be argued that some of the stability over time of accident record in a group is simply due to differences in experience, with older drivers having consistently fewer accidents. It should be evident from the present results that if such an effect exists, it is much smaller than the accident proneness effect.

\subsection{Methodology and consequences}

One important distinction between concepts needs to be made. In the present paper, the term 'stability' has been used, while in many of the papers referenced it is instead the reliability of accident record that is discussed (but correlations reported). Now, stability refers to how similar the accident record is over time, but also hints at the supposed, and much greater, similarity over time of accident-causing behaviour, which lies behind the actual crashes. Reliability, on the other hand, is more of a statistical/methodological concept, which tells us how much error we can expect in a certain situation (e.g. when using a population with a certain mean number of accidents per year, for a specified period). Many researchers may therefore be right in concluding that accidents are indeed very unreliable as a criterion (when the mean is low). However, it would sometimes seem like not all have maintained the distinction between the statistic, which they calculated for a certain period, and the wider picture of stability. Instead, they seem to have come to the conclusion that if accidents are unreliable here and now, they must be so for all time periods. It should be apparent from the present results that this is not so. The results presented here seem to indicate that the intercorrelations increase linearly with the mean number of accidents in the population. This, however, is of course not possible in the long run, as it implies that the association would be perfect after $\mathrm{n}$ years (in the presently used population 14 years for All accidents). It is instead 
expected that the association is somewhat curvilinear. However, there is currently a lack of published data in the range of 15-20 accidents (i.e. samples with such means), lying between the results quoted here and those of Häkkinen (1979) and Blasco, Prieto and Cornejo (2003), whose high-risk, longitudinal samples do not fit into the general picture (Figure 1), unless curvilinearity is assumed.

It might be added that Peck (1993) presented calculations on the maximum attainable correlation between accidents and a 'perfect predictor', given the variance of the former. In essence, what Peck was saying was the same thing as what has been pointed out here; if variance is low, correlations will be small, no matter how good the predictor, i.e. the actual association between the variables.

One of the conclusions drawn from some of the low-correlation-between-time-periods studies referenced in the introduction was that it would be fairly useless to exclude the high-accident drivers from driving, because they were few, and most of them did not repeat their high number of crashes again in the next time period. However, the present results indicate that these results and thinking were faulty, and simply artefacts of the short time periods and lowrisk populations utilized. If longer periods had been used, the effect of removing drivers would have been larger. After the many decades of criticism of the accident proneness theory, we tentatively suggest that the statistical arguments that caused it to fall into disrepute may well have been rather prematurely based. The positive results of the policy to exclude highaccident involved drivers from driving within a transportation company for an eight-year period was reported by Rawson (1944) but does otherwise not seem to have been evaluated or reported as being a policy advocated by transportation companies currently, perhaps because of the consensus has been that such a policy would be futile given the early arguments surrounding the notion of accident proneness. Further research is required to replicate the findings of the analyses here, and if confirmed has practical implications for 
organizations with major fleets. Driving for work increases the risk of being involved in a crash by about $50 \%$ (Broughton et al, 2003) and training interventions targeting accident involved drivers who are likely to go on to have more crashes may have a significant impact on work-related road safety.

It might be noted here that there does not seem to be any effect of low means such that the correlation coefficients become smaller than expected at the low end, as could possibly be expected due to the increasing violation of the assumption of normality of the distribution. Instead, these values conform to a linear function. This shows that the Pearson correlation is extremely robust, and useful, even when the normal distribution assumption is violated (as when means are very low).

It has been suggested that the term accident proneness should be replaced by accident liability, i.e. the risk of having an accident, not necessarily by causing it. However, this broader term and thinking would seem to be even less theoretical than the accident proneness concept, and although it does stress the importance of the environment and exposure, few if any predictions would seem to follow. Accident proneness, on the other hand, predicts such practically important effects as the association between different types of accidents. It is therefore suggested that accident proneness should be revived into traffic research, and attempts made to develop it further. It is not the theory that is deficient, but the previous interpretations of the results.

\section{Acknowledgements}

The accident data was kindly provided by a major British bus company. We are also grateful to Jenny Stannard (Cranfield University) for extracting the relevant data from the company database. An anonymous reviewer provided very thorough, knowledgeable and helpful feedback, for which we are grateful. 


\section{References}

Adelstein, A. M. (1952). Accident proneness; a criticism of the concept based on analysis of shunter's accidents. Journal of the Royal Statistical Society, 115, 111-116.

Arbous, A. G., \& Kerrich, J. E. (1951). Accident statistics and the concept of accident proneness. Biometrics, 7, 340-432.

Arthur, W., Jr., \& Graziano, W. G. (1996). The Five-factor model, conscientiousness, and driving accident involvement. Journal of Personality, 64, 593-618.

Avolio, B. J., Kroeck, K. G., \& Panek, P. E. (1985). Individual differences in informationprocessing ability as a predictor of motor vehicle accidents. Human Factors, 27, 577-589.

Bach, H., Bickel, H., \& Biehl, B. (1975). Validierung von Testverfahren zur Fahrer-Auslese am Unfallkriterium. Zeitschrift fur Verkehrssicherheit, 21, 27-38.

Baker, J. S. (1929). Do traffic accidents happen by chance? National Safety News, 20, 12-14.

Baker, J. S. (1932). What can we do for high-accident drivers? National Safety News, 25, 19$20,63$.

Blasco, R. D., Prieto, J. M., \& Cornejo, J. M. (2003). Accident probability after accident occurrence. Safety Science, 41, 481-501. 
Brandaleone, H., \& Flamm, E. (1955). Psychological testing: Effect on the accident frequency of bus operators. Industrial Medicine and Surgery, 24, 296-298.

Broughton, J., Baughan, C. J., Pearce, L., Smith, L., \& Buckle, G. (2003). Work-related road accidents. TRL Report 582. Crowthorne: Transport Research Laboratory.

Burg, A. (1970). The stability of driving record over time. Accident Analysis and Prevention, 2, 57-65.

Cameron, C. (1975). Accident proneness. Accident Analysis and Prevention, 7, 49-53.

Cation, W. L., Mount, G. E. \& Brenner, R. (1951). Variability of reaction time and susceptibility to automobile accidents. Journal of Applied Psychology, 35, 101-107.

Cresswell, W. L., \& Froggatt, P. (1963). The causation of bus driver accidents: An epidemiological study. London, University Press.

Dobson, A., Brown, W., Ball, J., Powers, J., \& McFadden, M. (1999). Women drivers' behaviour, socio-demographic characteristics and accidents. Accident Analysis and Prevention, 31, 525-535.

Dorn, L., \& af Wåhlberg, A. E. (in press). Work related road safety: An analysis based on UK bus driver performance. Risk Analysis: An International Journal, 
Farmer, E., \& Chambers, E. G. (1929). A study of personal qualities in accident proneness and proficiency. Industrial Health Research Board Report No 55.

Farmer, E. \& Chambers, E. G. (1939). A study of accident proneness among motor drivers. Industrial Health Research Board, Medical Research Council, Report 84. Her Britannic Majesty's Stationary Office, London.

Forbes, T. W. (1939). The normal automobile driver as a traffic problem. Journal of General Psychology, 20, 471-474.

Gebers, M. A. (2003). An Inventory of California Driver Accident Risk Factors. California Department of Motor Vehicles.

Gebers, M. A., \& Peck, R. C. (1994). An Inventory of California Driver Accident Risk Factors. California Department of Motor Vehicles.

Goldstein, L. G., \& Mosel, J. N. (1958). A factor study of drivers' attitudes, with further study on driver aggression. Highway Research Board Bulletin 172.

Greenwood, M., \& Woods, H. M. (1919). The incidence of industrial accidents upon individuals with specific reference to multiple accidents. Industrial Fatigue Research Board, Report No 4. London: His Majesty's Stationary Office. 
Gully, S. M., Whitney, D. J., \& Vanosdall, F. E. (1995). Prediction of police officers' traffic accident involvement using behavioral observations. Accident Analysis and Prevention, 27, $355-362$.

Harrington, D. M. (1972). The young driver follow-up study: An evaluation of the role of human factors in the first four years of driving. Accident Analysis and Prevention, 4, 191240.

Häkkinen, S. (1958). Traffic accidents and driver characteristics. Doctoral thesis, Finland's Institute of Technology.

Kerr, W. A. (1957). Complementary theories of safety psychology. Journal of Social Psychology, 45, 3-9.

Kirchner, W. K. (1961). The fallacy of accident proneness. Personnel, 38, 34-37.

Maritz, J. S. (1950). On the validity of inferences drawn from the fitting of Poisson and negative binomial distribution to observed accident data. Psychological Bulletin, 47, 434-443.

McBain, W. N. (1970). Arousal, monotony, and accidents in line driving. Journal of Applied Psychology, 54, 509-519.

McKenna, F. P. (1983). Accident proneness: A conceptual analysis. Accident Analysis and Prevention, 15, 65-71. 
McKenna, F. P., Duncan, J. \& Brown, I. D. (1986). Cognitive abilities and safety on the road: a re-examination of individual differences in dichotic listening and search for embedded figures. Ergonomics, 29, 649-663.

Milosevic, S., \& Vucinic, S. (1975). Statistical study of tram drivers' accidents. Accident Analysis and Prevention, 7, 1-7.

Mintz, A. (1954). The inference of accident liability from the accident record. Journal of Applied Psychology, 38, 41-46.

Mintz, A. (1956). A methodological note on time intervals between consecutive accidents. Journal of Applied Psychology, 40, 189-191.

Mintz, A., \& Blum, M. L. (1949). A re-examination of the accident proneness concept. Journal of Applied Psychology, 33, 195-211.

Newbold, E. (1927). Practical applications of the statistics of repeated events, particularly industrial accidents. Journal of the Royal Statistical Society, 90, 487-547.

Peck, R. C. (1993). The identification of multiple accident correlates in high risk drivers with specific emphasis on the role of age, experience and prior traffic violation frequency. Alcohol, Drugs and Driving, 9, 145-166. 
Peck, R. C. \& Kuan, J. A. (1983). A statistical model of individual accident risk prediction using driver record, territory and other biographical factors. Accident Analysis and Prevention, 15, 371-393.

Peck, R. C., McBride, R. S., \& Coppin, R. S. (1971). The distribution and prediction of driver accident frequencies. Accident Analysis and Prevention, 2, 243-299.

Porter, C. S. (1988). Accident proneness: A review of the concept. In D. J. Oborne (Ed.) International Reviews of Ergonomics: Current Trends in Human Factors Research and Practices, Vol 2, pp. 177-206. London: Taylor \& Francis.

Quimby, A. R., Maycock, G., Carter, I. D., Dixon, R., \& Wall, J. G. (1986). Perceptual abilities of accident involved drivers. TRRL Research Report 27. Crowthorne: Transport and Road Research Laboratory.

Rawson, A. J. (1944). Accident proneness. Psychosomatic Medicine, 6, 88-94.

Slocombe, C. S., \& Brakeman, E. E. (1930). Psychological tests and accident proneness. British Journal of Psychology, 21, 29-38.

Stewart, R. J., \& Campbell, B. J. (1972). The statistical association between past and future accidents and violations. Chapel Hill: University of North Carolina

Tillman, W. A., \& Hobbs, G. E. (1949). The accident-prone automobile driver: A study of the psychiatric and social background. American Journal of Psychiatry, 106, 321-331. 
West, R., Elander, J., \& French, D. (1992). Decision making, personality and driving style as correlates of individual crash risk. TRRL Contractor Report 309. Crowthorne: Transport and Road Research Laboratory.

Wong, W. A., \& Hobbs, G. E. (1949). Personal factors in industrial accidents - a study of accident proneness in an industrial group. Industrial Medicine, 18, 291-294.

af Wåhlberg, A. E. (2005). Differential accident involvement of bus drivers. In L. Dorn (Ed.) Driver Behaviour and Training, Volume II, pp. 383-391. Aldershot: Ashgate. Second International Conference on Driver Behaviour and Training. Edinburgh 15-17 November, 2005.

af Wåhlberg, A. E. (submitted). Bus driver accident record; stability over time, exposure and culpability.

af Wåhlberg, A. E. (forthcoming). Driver behaviour and accident research methodology; unresolved problems.

af Wåhlberg, A. E., \& Dorn, L. (2007). Culpable versus non-culpable traffic accidents; what is wrong with this picture? Journal of Safety Research, 38, 453-459.

van Zelst, R. H. (1954). The effect of age and experience upon accident rate. Journal of Applied Psychology, 38, 313-317. 
Table 1. Descriptive data for the samples of bus drivers; means and standard deviations for age, years of work for the bus company, and number of accidents during the time period 2001-2005 for three different levels of culpability.

\begin{tabular}{|l|l|l|l|l|l|l|}
\hline Sample & $\mathrm{N}$ & Age & Experience & No fault & Part fault & Sole fault \\
\hline 1 & 465 & $46.3 / 9.1(\mathrm{~N}=407)$ & $9.9 / 8.9$ & 2.39 & 0.28 & 2.07 \\
\hline 2 & 628 & $46.0 / 8.7$ & $11.5 / 9.5$ & 2.66 & 0.27 & 2.18 \\
\hline 3 & 141 & $46.5 / 8.7$ & $12.6 / 8.7$ & 3.69 & 0.34 & 2.14 \\
\hline 4 & 460 & $47.3 / 9.0$ & $9.5 / 8.3$ & 2.08 & 0.34 & 2.03 \\
\hline 5 & 518 & $46.0 / 9.7$ & $9.2 / 9.0$ & 2.26 & 0.29 & 1.89 \\
\hline
\end{tabular}


Table 2: The correlations between number of accidents per driver per single years. Mean correlation over all samples for All accidents .279 and At fault accidents .210

\begin{tabular}{|c|c|c|c|c|c|c|c|c|}
\hline \multicolumn{9}{|c|}{ Sample $1, \mathrm{~N}=465$ All correlations $\mathrm{p}<.01$. } \\
\hline & \multicolumn{4}{|c|}{ All accidents } & \multicolumn{4}{|c|}{ At fault accidents } \\
\hline Years & 2001 & 2002 & 2003 & 2004 & 2001 & 2002 & 2003 & 2004 \\
\hline 2002 & .298 & & & & .178 & & & \\
\hline 2003 & .274 & .322 & & & .236 & .249 & & \\
\hline 2004 & .273 & .310 & .306 & & .144 & .202 & .156 & \\
\hline 2005 & .172 & .289 & .194 & .312 & .156 & .314 & .157 & .244 \\
\hline \multicolumn{9}{|c|}{ Sample 2, $\mathrm{N}=628$ All correlations $\mathrm{p}<.05$} \\
\hline & \multicolumn{4}{|c|}{ All accidents } & \multicolumn{4}{|c|}{ At fault accidents } \\
\hline Years & 2001 & 2002 & 2003 & 2004 & 2001 & 2002 & 2003 & 2004 \\
\hline 2002 & .262 & & & & .149 & & & \\
\hline 2003 & .270 & .253 & & & .199 & .174 & & \\
\hline 2004 & .195 & .224 & .187 & & .129 & .122 & .101 & \\
\hline 2005 & .233 & .254 & .294 & .195 & .167 & .204 & .228 & .133 \\
\hline \multicolumn{9}{|c|}{ Sample $3, \mathrm{~N}=141$ All correlations $\mathrm{p}<.05$ except $\mathrm{ns}$. } \\
\hline & \multicolumn{4}{|c|}{ All accidents } & \multicolumn{4}{|c|}{ At fault accidents } \\
\hline Years & 2001 & 2002 & 2003 & 2004 & 2001 & 2002 & 2003 & 2004 \\
\hline 2002 & .357 & & & & .472 & & & \\
\hline 2003 & .467 & .285 & & & .190 & $\begin{array}{l}.115 \\
\mathrm{~ns}\end{array}$ & & \\
\hline 2004 & .406 & .280 & .263 & & .296 & $\begin{array}{l}.131 \\
\mathrm{~ns}\end{array}$ & .236 & \\
\hline 2005 & .313 & .378 & .384 & $\begin{array}{l}.158 \\
\text { ns }\end{array}$ & .261 & .323 & .215 & .215 \\
\hline \multicolumn{9}{|c|}{ Sample 4, N=460 All correlations $\mathrm{p}<.001$} \\
\hline & \multicolumn{4}{|c|}{ All accidents } & \multicolumn{4}{|c|}{ At fault accidents } \\
\hline Years & 2001 & 2002 & 2003 & 2004 & 2001 & 2002 & 2003 & 2004 \\
\hline 2002 & .286 & & & & .240 & & & \\
\hline 2003 & .198 & .188 & & & .199 & .148 & & \\
\hline 2004 & .288 & .219 & .172 & & .175 & .201 & .132 & \\
\hline 2005 & .195 & .146 & .137 & .191 & .221 & .115 & .129 & .161 \\
\hline \multicolumn{9}{|c|}{ Sample 5, N=518 All correlations $\mathrm{p}<.001$} \\
\hline & \multicolumn{4}{|c|}{ All accidents } & \multicolumn{4}{|c|}{ At fault accidents } \\
\hline Years & 2001 & 2002 & 2003 & 2004 & 2001 & 2002 & 2003 & 2004 \\
\hline 2002 & .293 & & & & .220 & & & \\
\hline 2003 & .238 & .287 & & & .200 & .149 & & \\
\hline 2004 & .273 & .325 & .352 & & .165 & .189 & .255 & \\
\hline 2005 & .262 & .299 & .283 & .319 & .220 & .210 & .173 & .204 \\
\hline
\end{tabular}


Table 3: The correlations between accidents for different time periods, and their means summed. First section; the means of the correlations in Table 2 (calculated as the square root of the mean of the squared correlations). Second section; the correlations between the accidents of 2001-2002 versus 2003-2004, and the means of these variables summed. Third section; the correlations between the accidents of 2001-2002 versus 2003-2005, and the means of these variables summed. All correlations of sections two and three significant at $\mathrm{p}<.01$.

\begin{tabular}{|c|c|c|}
\hline \multicolumn{3}{|c|}{ One by one year periods (means for Table 2 matrixes), mean for All=.276, At fault=.206 } \\
\hline Sample & Mean correlation & Mean of accidents \\
\hline 1 All & .279 & 1.90 \\
\hline 1 At fault & .210 & 0.94 \\
\hline 2 All & .239 & 2.04 \\
\hline 2 At fault & .165 & 0.98 \\
\hline 3 All & .339 & 2.47 \\
\hline 3 At fault & .261 & 0.99 \\
\hline 4 All & .208 & 1.78 \\
\hline 4 At fault & .177 & 0.95 \\
\hline 5 All & .295 & 1.77 \\
\hline 5 At fault & .201 & 0.87 \\
\hline \multicolumn{3}{|c|}{ Two by two year periods (2001-2002x2003-2004); mean for All=.437, At fault=.301 } \\
\hline Sample & Correlation & Mean of accidents \\
\hline 1 All & .452 & 3.98 \\
\hline 1 At fault & .359 & 2.02 \\
\hline 2 All & .384 & 4.26 \\
\hline 2 At fault & .281 & 2.07 \\
\hline 3 All & .536 & 4.93 \\
\hline 3 At fault & .264 & 1.92 \\
\hline 4 All & .367 & 3.67 \\
\hline 4 At fault & .305 & 1.97 \\
\hline 5 All & .423 & 3.58 \\
\hline 5 At fault & .285 & 1.75 \\
\hline \multicolumn{3}{|c|}{ Two by three year periods (2001-2002x2003-2005), mean for All=.476, At fault=.365 } \\
\hline Sample & Correlation & Mean of accidents \\
\hline 1 All & .475 & 4.74 \\
\hline 1 At fault & .420 & 2.35 \\
\hline 2 All & .429 & 5.11 \\
\hline 2 At fault & .331 & 2.45 \\
\hline 3 All & .593 & 6.17 \\
\hline 3 At fault & .369 & 2.48 \\
\hline 4 All & .390 & 4.45 \\
\hline 4 At fault & .347 & 2.37 \\
\hline 5 All & .470 & 4.44 \\
\hline 5 At fault & .353 & 2.18 \\
\hline
\end{tabular}


Table 4: The mean of correlations (calculated as the square root of the mean of the squared correlations) between single years with other years, as presented in Table 2, ordered by how far apart the years were.

\begin{tabular}{|l|l|l|l|l|l|l|}
\hline & \multicolumn{3}{|l|}{ All accidents } & \multicolumn{3}{l|}{ At fault accidents } \\
\hline Years apart & 0 & 1 & $2-3$ & 0 & 1 & $2-3$ \\
\hline Mean correlation & .271 & .284 & .274 & .212 & .188 & .216 \\
\hline
\end{tabular}




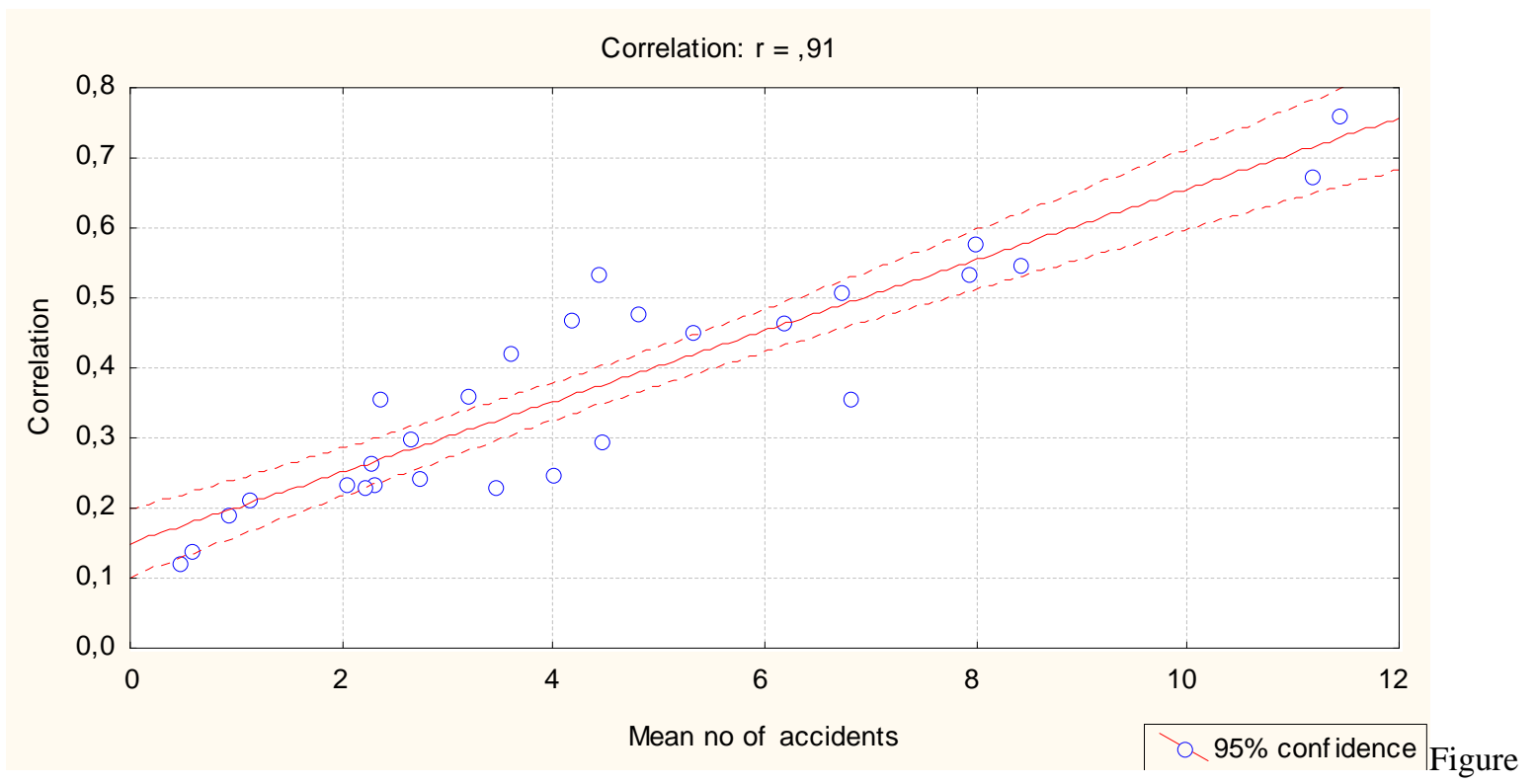

1: The association between the mean number of accidents and size of correlations between accident record in different time periods (usually half-half), for professional (bus and tram) driver samples. $r=.91, \mathrm{~N}=28, \mathrm{p}<.001$. Two outlier cases deleted. Reproduced from af Wåhlberg (forthcoming). The values taken from Bach, Bickel \& Biehl, 1975; Blasco, Prieto \& Cornejo, 2003; Creswell \& Froggatt, 1963; Farmer \& Chambers, 1939; Häkkinen, 1958; McKenna, Duncan \& Brown, 1986; Milosevic \& Vucinic, 1975; af Wåhlberg (submitted). 


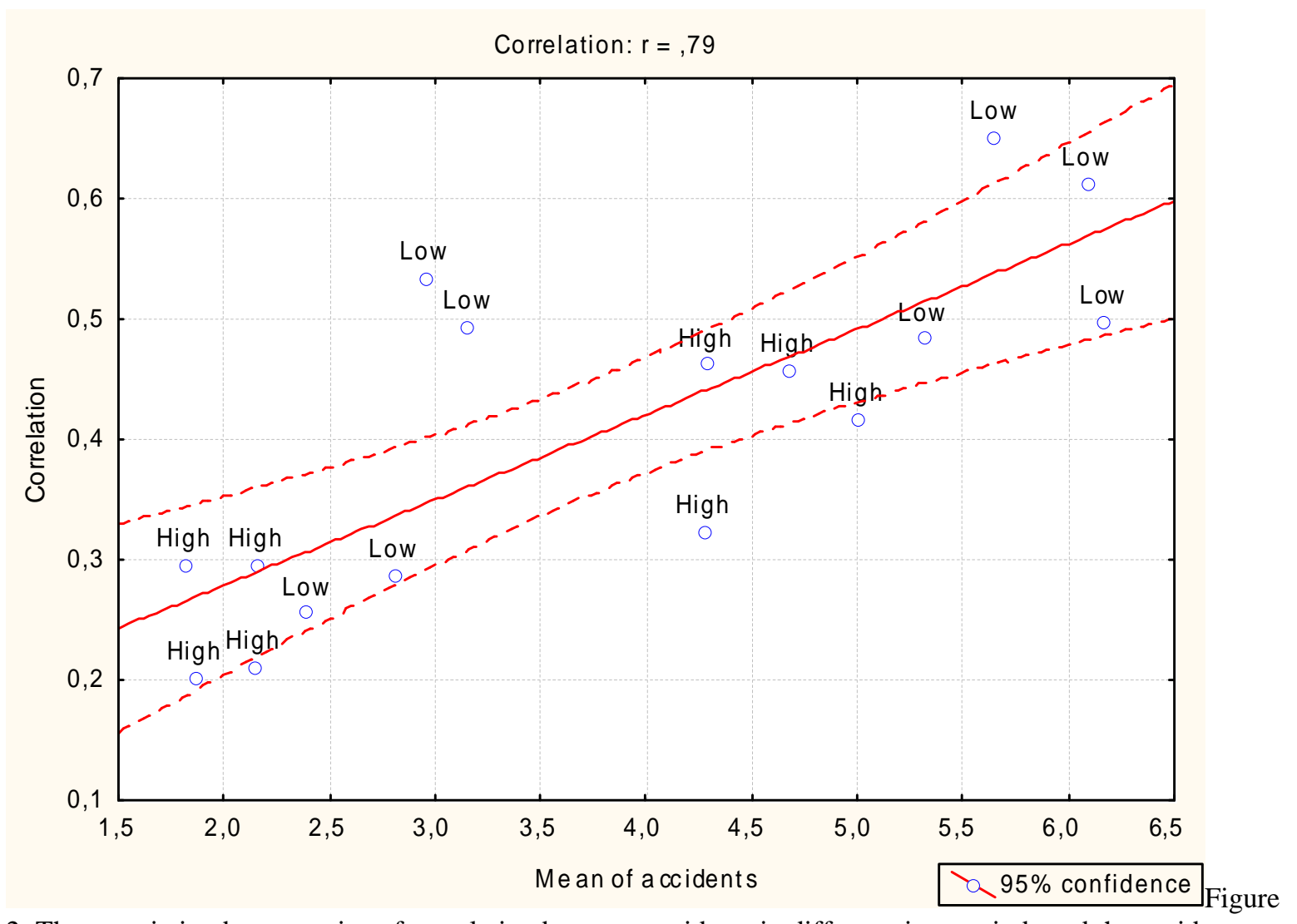

2: The association between size of correlation between accidents in different time periods and the accidents means of the total periods, for samples 1-2 and 4-5 (3 excluded due to too few inexperienced drivers). The points to the left of the 3.5 value are calculated for 2001/2002, and the others for 2001-2002/2003-2005. High experience drivers are those with more than one year of experience at the beginning of 2001. 